\title{
AS ROCHAS GRANITÓIDES DA SÉRIE SHOSHONITICA
}

\author{
LAURO V.S. NARDI*
}

\begin{abstract}
Although the investigation of the relationship between granitic rocks and magmatic series has been the subject of several papers, the importance of granitoids of shoshonitic series has been neglected. In this paper, the main characteristics of these granitoids are discussed and their tectonic and metallogenetic importance is emphasized. Granitoids of shoshonitic series show petrographic features which are similar to those of calc-alkaline series, while the major element patterns are ambiguous, suggesting alkaline or calc-alkaline trends. These granitoids are characterized by high concentrations of $\mathrm{Ba}, \mathrm{Sr}, \mathrm{Rb}$ and low concentrations of $\mathrm{Zr}, \mathrm{Nb}$, except for highly differentiated terms. REE show normalized patterns which are similar to those of calc-alkaline granitoids, but frequently with higher $\mathrm{CeN}_{\mathrm{N}} / \mathrm{YbN}_{\mathrm{N}}$ ratios. Granitic magmatism of shoshonitic affinity is related to extensional tectonic periods in back arc areas in continental margins or in very mature island arcs. Porphyry copper deposits have been described in some of these plutons. In the Sul-Rio-Grandense Shield two large granitic intrusions with shoshonitic affinity have been reported, being associated with precambrian shoshonitic volcanic rocks.
\end{abstract}

INTRODUÇÃO Grande parte das rochas graníticas tem sua gênese relacionada com processos de fusão crustal tanto de rochas orto como parametamórficas. A diferenciação de magmas dominantemente mantélicos, parece no entanto o mecanismo mais importante de geração de granitóides, advindo daí a necessidade da investigação do relacionamento das intrusð̃es graníticas com as séries magmáticas. Com este objetivo, granitóides de séries cálcio-alcalina, alcalina $\mathrm{e}$ toléítica têm sido descritos em vários trabalhos e caracterizados em diversos diagramas geoquímicos e mineralógicos (Brown 1981, Lameyre 1980, Rogers et al. 1980, e outros).

A ocorrência de granitóides da denominada série shoshonítica ou monzonítica tem sido apontada por autores como Morrison (1980), Tauson (1983), Lameyre \& Bowden (1982), Pearce et al. (1984), entretanto sua caracterização é ainda difícil e questionada por vários petrólogos e geoquímicos.

$O$ objeto do presente trabalho é destacar a importância dessas rochas tanto do ponto de vista geológico como econômico e discutir algumas de suas características de maior relevância.

A série shoshonitica As séries magmáticas são associações de rochas ígneas com uma gênese comum, que pode ser prevista com base em processos ditos de diferenciação (Hughes 1982). Logo no início deste século, foram reconhecidas as séries alcalina e não-alcalina (ou subalcalina) em função do teor de $\mathrm{Na}_{2} \mathrm{O}+\mathrm{K}_{2} \mathrm{O}$ em relação a $\mathrm{SiO}_{2}$. Entre as séries não-alcalinas, verificou-se que algumas apresentam um enriquecimento em ferro nos termos intermediários evidenciado geralmente no diagrama AFM $\left(\mathrm{Na}_{2} \mathrm{O}+\mathrm{K}_{2} \mathrm{O}\right.$ versus $\mathrm{FeO}$ (total) versus $\mathrm{MgO}$ ). Esta série foi denominada tolética enquanto as desprovidas desta característica foram ditas cálcio-alcalinas (Miyashiro 1974). Uma quarta série magmáti$\mathrm{ca}$, a shoshonítica, pode ser adicionada a essas, conforme a redefinição de Morrison (1980). No que diz respeito à química dos elementos maiores, a série shoshonítica é caracterizada pela elevada razão $\mathrm{K}_{2} \mathrm{O} / \mathrm{Na}_{2} \mathrm{O}$, principalmente nos termos básicos e intermediários. Outras séries magmáticas têm sido sugeridas, como a transicional (Girod 1978) e a komatítica (Arndt \& Nisbet 1982). As características petrográficas e químicas das séries magmáticas têm sido revisada por vários autores, destacando-se Ewart (1979), Hughes (1983), Girod (1978) e Baker (1978). Os elementos-traços constituem parâmetros da mais alta significação na distinção dessas séries, como é bem exemplificado nos trabalhos de Pearce (1982, 1983), Baker (1982) e outros.

A série shoshonítica foi sugerida por Joplin (1965) e engloba rochas com alto teor de $\mathrm{K}_{2} \mathrm{O}$. Morrison (1980) restringiu este termo para séries de rochas saturadas em $\mathrm{SiO}_{2}$ e descreveu suas principais características químicas.

- basaltos aproximadamente saturados $\mathrm{em} \mathrm{SiO}_{2}$;

- baixo enriquecimento em ferro;

- elevado $\mathrm{Na}_{2} \mathrm{O}+\mathrm{K}_{2} \mathrm{O}$ (maior que $5 \%$ );

- alta razão $\mathrm{K}_{2} \mathrm{O} / \mathrm{Na}_{2} \mathrm{O}$ (de 0,6 a 1,0 para basaltos e andesitos);

- trends com forte inclinação positiva no diagrama $\mathrm{K}_{2} \mathrm{O}$ versus $\mathrm{SiO}_{2}$ para rochas com até $57 \%$ de $\mathrm{SiO}_{2}$;

- enriquecimento em $\mathrm{P}, \mathrm{Rb}, \mathrm{Sr}, \mathrm{Ba}, \mathrm{Pb}$ e terras-raras leves.

- baixo teor de $\mathrm{TiO}_{2}$ (menor que $1,3 \%$ );

- alto, mas variável conteúdo de $\mathrm{Al}_{2} \mathrm{O}_{3}$;

- elevada razão $\mathrm{Fe}_{2} \mathrm{O}_{3} / \mathrm{FeO}$ (maior que 0,5).

As rochas pertencentes às séries shoshoníticas fanerozóicas são geralmente associadas a ambientes orogênicos maduros, sucedendo as séries toleíticas e cálcio-alcalinas. Baker (1978) observou que elas representam as últimas manifestações magmáticas de um ciclo orogênico, localizando-se nas porções mais distais das fossas oceânicas. Jakes \& White (1972) notaram que as rochas cálcio-alcalinas de arcos de ilhas gradam para rochas com baixo $\mathrm{K}_{2} \mathrm{O}$ no sentido oceânico e para rochas shoshoníticas no sentido continental do arco. Existem casos em que a relação entre a zona de sub. ducção e a ocorrência de rochas shoshoníticas não é clara, como no Yellowstone Park, onde as mesmas foram originalmente definidas (Hughes 1983). Também as lavas shoshoniticas de New South Wales, Austrália, de acordo com Carr \& Fardy (1984) não são diretamente relaciondas com magmatismo de zona de Benioff, tendo sido geradas após o término da subduç̧ão. Morrison (1980), entretanto, enfati- 
zou que o ambiente tectônico das séries shoshoníticas é bem definido e sugere que o reconhecimento de séries deste tipo pode colaborar na elucidação da história tectônica de áreas orogênicas mais antigas.

Tauson (1983) caracterizou a série latítica do ponto de vista geoquímico e metalogenético, e salientou que a mesma equivale à série shoshonítica descrita por Morrison (1980). O autor destaca que a série latítica é constituída por shoshonitos, latitos, dacitos potássicos e riolitos, bem como por intrusivas monzoníticas, que mostram elevadas concentrações de $\mathrm{K}_{2} \mathrm{O}$, voláteis (principalmente flúor) e elementos litófilos como $\mathrm{Ba}$; $\mathrm{Sr}$ e Rb. O mesmo autor observou que esta série ocorre na zona de retaguarda de arcos magmáticos e em zonas móveis intracontinentais.

Tsvetkov (1984) enfatizou as diferenças entre a série alcalina (Miyashiro 1974) e a shoshonítica, tendo ressaltado que as rochas shoshoníticas só são geradas quando existe uma crosta "granítica-metamórfica" já formada. Segundo o mesmo, elas são geradas por magmas mantélicos contaminados por assimilação de rochas graníticas ou pelíticas crustais.

Em áreas arqueanas, as rochas da série shoshonítica parecem ser relativamente raras. Hubregtse (1976) descreveu uma seqüência de rochas tipicamente shoshonítica na área de Jackson Bay, do Greenstone Belt de Knee Lake-Oxford Lake, Província Superior de Manitoba, Canadá. Aquele autor concluiu que o modelo de arco de ilhas é incompatí. vel com a evolução deste cinturão.

No Brasil, são raras as referências de rochas da série shoshonítica, provavelmente devido à carência de dados químicos dissponíveis e também à controvérsia que ainda se verifica em torno deste termo. Nardi \& Lima (1985) e Lima (1985) descreveram a Associação Shoshonítica de Lavras do Sul, de idade em torno de $640 \mathrm{Ma}$, lozalizada na porção sudoeste do Escudo Sul-Rio-Grandense. A situação geotectônica da mesma não é ainda bem estabelecida, sendo para tanto necessária uma maior compreensão dos eventos geológicos registrados na região. A Ássociação Shoshonítica de Lavras do Sul compreende, além de lavas, hipabissais e piroclásticas, a zona central do Complexo Granítico Lavras. $O$ Monzogranito Santa Rita (Naumann 1985) pode, por suas características geoquímicas, ser incluído nesta associação.

OS GRANITÓIDES DA SÉRIE SHOSHONITICA ROchas granitóides da série shoshonítica têm sido raramente reconhecidas tanto pelo caráter controvertido da conceituação de série shoshonítica como pela dificuldade de vinculação das rochas graníticas com seus possíveis correspondentes extrusivos. Tais dificuldades, como observou Pearce $e t$ al. (1984), provêm de diversos fatores que podem influenciar a evolução petrogenética dos granitóides: fracionamen. to e acumulação de cristais, assimilação de crosta continental, redistribuição e perda de elementos devido à ação de voláteis, cristalização de fases acessórias enriquecidas em elementos-traços, etc.

Nas classificações de Chappell \& White (1974) e Pearce (1983), os granitóides da série shoshonítica são englobados como tipo I ou tipo I Caledoniano. Mais comumente são incluídos na série cálcio-alcalina ou na alcalina. Vários autores no entanto têm constatado sua individualidade:

- Lameyre \& Bowden (1982) reconheceram com base em classificações modais no diagrama QAP uma série "cálcio-al- calina monzogranítica";

- Pearce et al (1984) distinguiram granitóides da série shoshonítica dos cálcio-alcalinos, entre as rochas relacionadas com arcos magmáticos;

- Pagel \& Leterrier (1980) constataram a afinidade shoshonítica do maciço de Ballons, França;

- Tauson (1983) salientou a ocorrência de rochas monzoníticas associadas às séries latíticas citando monzogranitos da porção leste de Transbaykalia como exemplos.

Com o objetivo de revisar e discutir algumas das mais importantes características dos granitóides de séries shoshoníticas, selecionaram-se os seguintes exemplos da bibliografia disponível: intrusivas graníticas de Last Chance e Bingham, descritas por Moore (1973) e reconhecidas como shoshoniticas por Tauson (1983); o maciço granítico de Ballons (Pagel \& Leterrier 1980); os granitóides da região sudeste de Papua-Nova Guiné (Smith 1972); e os granitóides da zona central do Complexo Granítico Lavras e o Monzogranito Santa Rita, do Escudo Sul-Rio-Grandense, descritos, respectivamente, por Nardi (1984) e Naumann (1985). Esses granitóides são associados a séries vulcânicas shosho. níticas e mostram relações discordantes com as encaixan. tes mas não registram evidência de deformação regional.

De acordo com a classificação de Streckeisen (1976), são dominantemente monzonitos, granodioritos e granitos. Petrograficamente, assemelham-se aos granitóides do tipo I de Chappel \& White (1974) ou aos da série de magnetita granitóides de Ishiara (1977). Embora Smith (1972) haja assinalado a presença de aegirina-augita em alguns granitóides da série shoshonítica de Papua, o piroxênio augítico é o mais comum nos granitóides acima referidos. Os anfibólios são geralmente descritos como hornblenda. Na zona central do Complexo Granítico Lavras e no Monzogranito Santa Rita, são ferro-edenitas com razão $\mathrm{Fe} /(\mathrm{Fe}+\mathrm{Mg})$ menor que 0,75 . Nardi (1984), comparando anfibólios cálcicos de granitóides da série cálcio-alcalina, constatou que para os primeiros esta razão é geralmente menor que 0,75 enquanto nos granitóides da série alcalina esta razão se situa acima de 0,90 . Smith (1972) registrou a ocorrência de riebeckita em alguns granitóides da série shoshonitica de Papua. A biotita é abundante nos granitóides da série shoshonítica e reflete a concentração relativamente elevada de potássio e voláteis nos magmas shoshoníticos. Magnetita, por vezes titanifera, zírcão, apatita e esfeno são fases comumente presentes.

Geoquímica A composição química média de alguns granitóides de séries shoshoníticas, já referidos anteriormente, é apresentada na Tab. 1, juntamente com médias de rochas graníticas pós-arqueanas referidas por Condie (1982).

A tabela 2 apresenta algumas características de granitóides das séries abordadas neste trabalho, que incluem aqueles gerados por fusão parcial de sequiências dominantemente metassedimentares. É importante salientar que os granitóides gerados por fusão parcial de seqüências ortometamórficas apresentam características similares aos da série cálcioalcalina. No que diz respeito aos granitóides arqueanos, de modo geral admite-se a possibilidade de enquadramento nos grupos constantes na tabela 2 , no entanto eles apresentam particularidades como um elevado grau de fracionamento das terras-raras e um freqüente enriquecimento em $\mathrm{Ba}$ e $\mathrm{Sr}$ (Condie 1982): 
Na série shoshonitica são dominantes granitóides intermediários de caráter metaluminoso. Pearce et al. (1984) observaram que os arcos mais maturos os granitóides evoluem de cálcio-alcalinos para alcalicálcicos, de acordo com a nomenclatura sugerida por Peacock (1931). A figura 1 indica que os granitóides considerados neste trabalho são alcalicálcicos, devendo-se ressaltar a semelhança entre os trends dos granitóides shoshoníticos do Rio Grande do Sul e de Bingham. $O$ trend dos granitóides de Bingham, ilustrados na figura 1 , inclui rochas riolíticas. Destaque-se igualmente o caráter bastante diferenciado dos granitóides shoshoníticos do Rio Grande do Sul em relação às demais associações estudadas. As rochas graníticas da série shoshonítica de Papua (Smith 1972) são alcalicálcicas e mostram no entanto, uma tendência mais alcalina, que parece refletir a associação intima da série alcalina subsaturada com a shoshonítica ocorrente naquela região.

A figura 2 ilustra o comportamento dos granitóides da série shoshonítica no diagrama discutido por Brown (1982). Os granitóides estudados situamıse próximo ao limite entre as suítes de ambientes compressivos e distensivos, respectivamente os campos dos granitóides cálcio-alcalinos e alcalinos. De acordo com Brown (1982), o posicionamento dessas rochas no diagrama citado as identifica como associações magmáticas desenvolvidas em arcos de grande maturidade ou margens continentais.

No diagrama $\left(\mathrm{Na}_{2} \mathrm{O}+\mathrm{K}_{2} \mathrm{O}\right)$ versus $\mathrm{FeO}$ (total) versus MgO (Brown, 1981), os granitóides da série shoshonítica mostram padrões destituídos de enriquecimento em ferro nos termos intermediários (Fig. 3), diferenciando-os dos granitóides das séries toleíticas. Note-se igualmente que os
Tabela 1 - Composição química média de granitóides da série shoshonitica em relação a médias de granodioritos $e$ granitos

\begin{tabular}{lrrrrrrrr}
\hline & \multicolumn{1}{c}{$\mathbf{1}$} & \multicolumn{1}{c}{$\mathbf{2}$} & \multicolumn{1}{c}{$\mathbf{3}$} & \multicolumn{1}{c}{$\mathbf{4}$} & \multicolumn{1}{c}{5} & \multicolumn{1}{c}{6} & \multicolumn{1}{c}{$\mathbf{7}$} & \multicolumn{1}{c}{8} \\
\hline $\mathrm{SiO}_{2}$ & 70,18 & 59,70 & 57,01 & 66,07 & 70,03 & 59,25 & 66,90 & 72,10 \\
$\mathrm{TiO}_{2}$ & 0,32 & 0,83 & 0,63 & 0,44 & 0,38 & 0,84 & 0,57 & 0,37 \\
$\mathrm{Al}_{2} \mathrm{O}_{3}$ & 15,24 & 15,10 & 15,73 & 14,52 & 14,12 & 15,40 & 15,70 & 13,90 \\
$\mathrm{Fe}_{2} \mathrm{O}_{3}$ & 0,27 & 2,30 & 4,22 & $3,59 *$ & 2,30 & 2,85 & 1,33 & 0,86 \\
$\mathrm{FeO}$ & 2,30 & 3,30 & 2,96 & - & 1,70 & 3,00 & 2,59 & 1,67 \\
$\mathrm{MnO}$ & 0,04 & 0,09 & 0,14 & 0,07 & 0,06 & 0,45 & 0,07 & 0,06 \\
$\mathrm{MgO}$ & 0,61 & 4,20 & 4,42 & 2,16 & 0,81 & 3,65 & 1,57 & 0,52 \\
$\mathrm{CaO}$ & 1,79 & 5,30 & 5,20 & 2,78 & 2,11 & 4,60 & 3,56 & 1,33 \\
$\mathrm{Na}_{2} \mathrm{O}$ & 4,45 & 3,70 & 3,72 & 3,18 & 4,49 & 3,60 & 3,84 & 3,08 \\
$\mathrm{~K}_{2} \mathrm{O}$ & 3,78 & 4,00 & 4,27 & 5,12 & 3,38 & 4,75 & 3,07 & 5,46 \\
$\mathrm{P}_{2} \mathrm{O}_{5}$ & 0,10 & 0,43 & 0,46 & - & 0,12 & 0,47 & 0,21 & 0,18 \\
& & & & & & & & \\
$\mathrm{Ba}$ & 1.021 & 3.000 & 1,102 & 1.137 & 1,174 & 2.500 & 600 & 500 \\
$\mathrm{Sr}$ & 739 & 2.000 & 834 & 410 & 490 & 1.750 & 450 & 100 \\
$\mathrm{Zr}$ & 197 & 200 & 149 & - & 164 & 250 & 130 & 200 \\
$\mathrm{Nb}$ & 17 & 10 & - & - & - & 20 & - & - \\
$\mathrm{Rb}$ & 143 & - & - & 333 & 80 & - & 110 & 250 \\
$\mathrm{Y}$ & 19 & 20 & $<40$ & - & - & 158 & - & - \\
\hline
\end{tabular}

1. Zona central do Complexo Granítico Lavras (Nardi 1984); 2. intrusivas graníticas de Last Chance (Moore 1973); 3. granitóides shoshoníticos de Papua (Smith 1972); 4. monzogranitos do Maciço de Ballons (Pagel \& Leterrier 1980); 5. monzogranito Santa Rita 6. granitóides de Bingham (Moore 1972); 7. media de granodioritos pós-arqueanos (Condie 1982); 8. média de granitos pós-arquea(Condie 1982)

${ }^{*} \mathrm{Fe}_{2} \mathrm{O}_{3}=$ ferro total, elementos maiores em porcentagem e traços em ppm.

termos mais diferenciados da série shoshonítica se situam no campo dos granitos das séries alcalinas conforme Brown (1981).

Tabela 2 - Caracteristicas gerais dos granitóides das séries magmáticas e dos formados por fusão parcial das seqüências metassedimentares

\begin{tabular}{|c|c|c|c|c|c|}
\hline Série cálcio-alcalina & Série shoshonítica & Série alcalina & Série toleítica & Fusão crustal & \\
\hline $\begin{array}{l}\text { Tonalitos-granodioritos- } \\
\text { granitos }\end{array}$ & $\begin{array}{l}\text { Monzonitos-granodiori- } \\
\text { tos-monzogranitos }\end{array}$ & Sienitos-pertita granitos & Tonalitos & Granitos & \\
\hline $\begin{array}{l}\text { Anfibóljos cálcicos magn } \\
\text { nesianos e biotita }\end{array}$ & $\begin{array}{l}\text { Biotita e anfibólios cál- } \\
\text { cicos magnesianos }\end{array}$ & $\begin{array}{l}\text { Anfibólios sódicos, sódi- } \\
\text { co-cálcicos e biotita ani- } \\
\text { tica }\end{array}$ & $\begin{array}{l}\text { Piroxênios e anfibólios } \\
\text { cálcicos }\end{array}$ & Biotita e moscovita & \\
\hline $\begin{array}{l}\text { Magnetita-esfeno-ilmeni- } \\
\text { ta }\end{array}$ & Magnetita-esfeno & Magnetita-fluorita-zircão & $\begin{array}{l}\text { Magnetita-ilmenita zir- } \\
\text { cão }\end{array}$ & $\begin{array}{l}\text { Ilmenita-monazita-cor- } \\
\text { dierita }\end{array}$ & \\
\hline Metaluminosos & Metaluminosos & $\begin{array}{l}\text { Metaluminosos a peralca- } \\
\text { linos }\end{array}$ & Metaluminosos & Peraluminosos & \\
\hline $\begin{array}{l}\text { Cálcio-alcalinos (Pea- } \\
\text { cock) }\end{array}$ & Alcali-cálcicos & Alcalinos & Cálcicos . & - & \\
\hline $\begin{array}{l}\text { Teores médios de } \mathrm{Ba}, \mathrm{Sr} \\
\text { e } \mathrm{Rb}\end{array}$ & $\begin{array}{l}\text { Teores altos de } \mathrm{Ba}, \mathrm{Sr} \text { e } \\
\text { médio } \mathrm{Rb}\end{array}$ & $\begin{array}{l}\text { Teores variáveis de } \mathrm{Ba} \text {, } \\
\text { Sr e } \mathrm{Rb}\end{array}$ & $\begin{array}{l}\text { Teores baixos de } \mathrm{Ba}, \mathrm{Sr} \\
\text { e muito baixo } \mathrm{Rb}\end{array}$ & $\begin{array}{l}\text { Teores variáveis de } \mathrm{Ba} \text {, } \\
\text { Sr e muito alto } \mathrm{Rb}\end{array}$ & \\
\hline $\begin{array}{l}\text { Teores baixos de } \mathrm{Nb} e \\
\mathrm{Zr}\end{array}$ & $\begin{array}{l}\text { Teares baixos a médios, } \\
\text { de } \mathrm{Nb} \text { e } \mathrm{Zr}\end{array}$ & Teores altos de $\mathrm{Nb}$ e $\mathrm{Zr}$ & $\begin{array}{l}\text { Teores baixos a médios } \\
\text { đe } \mathrm{Nb} \text { e } \mathrm{Zr}\end{array}$ & $\begin{array}{l}\text { Teores baixos de } \mathrm{Nb} \text { e } \\
\mathrm{Zr}\end{array}$ & \\
\hline $\begin{array}{l}\text { Conteúdo de terras-raras } \\
\text { médio, fracionamento } \\
\text { moderado }\end{array}$ & $\begin{array}{l}\text { Conteúdo de terras-raras } \\
\text { médio, fracionamento } \\
\text { moderado a alto }\end{array}$ & $\begin{array}{l}\text { Conteúdo de terras-raras } \\
\text { elevado, fracionamento } \\
\text { baixo }\end{array}$ & $\begin{array}{l}\text { Conteúdo de terras-raras } \\
\text { médio, fracionamento } \\
\text { baixo }\end{array}$ & $\begin{array}{l}\text { Conteúdo de terras-ra- } \\
\text { ras baixo e fraciona- } \\
\text { mento variável }\end{array}$ & \\
\hline $\begin{array}{l}\text { Arcos de ilhas e margens } \\
\text { continentais ativas }\end{array}$ & $\begin{array}{l}\text { Arcos maturos, retaguar- } \\
\text { da de arcos magmáticos }\end{array}$ & Ambientes cratônicos & Ofiólitos & $\begin{array}{l}\text { Zonas de colisão con- } \\
\text { tinental, zonas de cisa- } \\
\text { lhamento }\end{array}$ & \\
\hline Cobre pórfiro (Cu-Mo) & $\begin{array}{l}\text { Cobre pórfiro }(\mathrm{Cu}) \mathrm{Sn} \text { - } \\
\mathrm{Cu}\end{array}$ & Sn e Nb-Ta & Cobre pórfiro (Cu-Au) & $\mathrm{Sn}-\mathrm{W}$ & \\
\hline
\end{tabular}




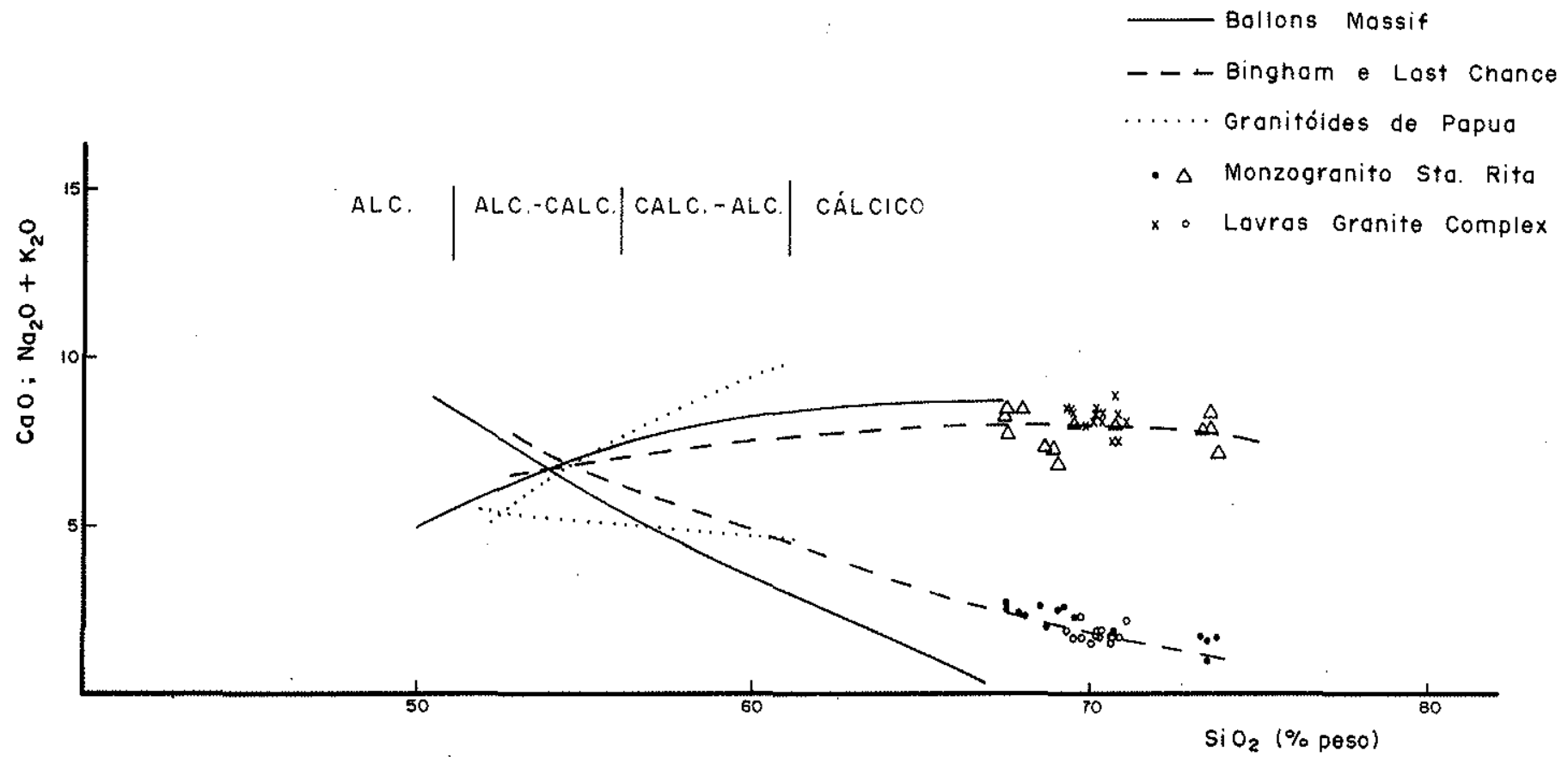

Figura 1 - Comportamento de granitóides da série shoshonitica no diagrama de Peacock (1931). Referências das associaçōes representadas constam do texto e da tabela 1.

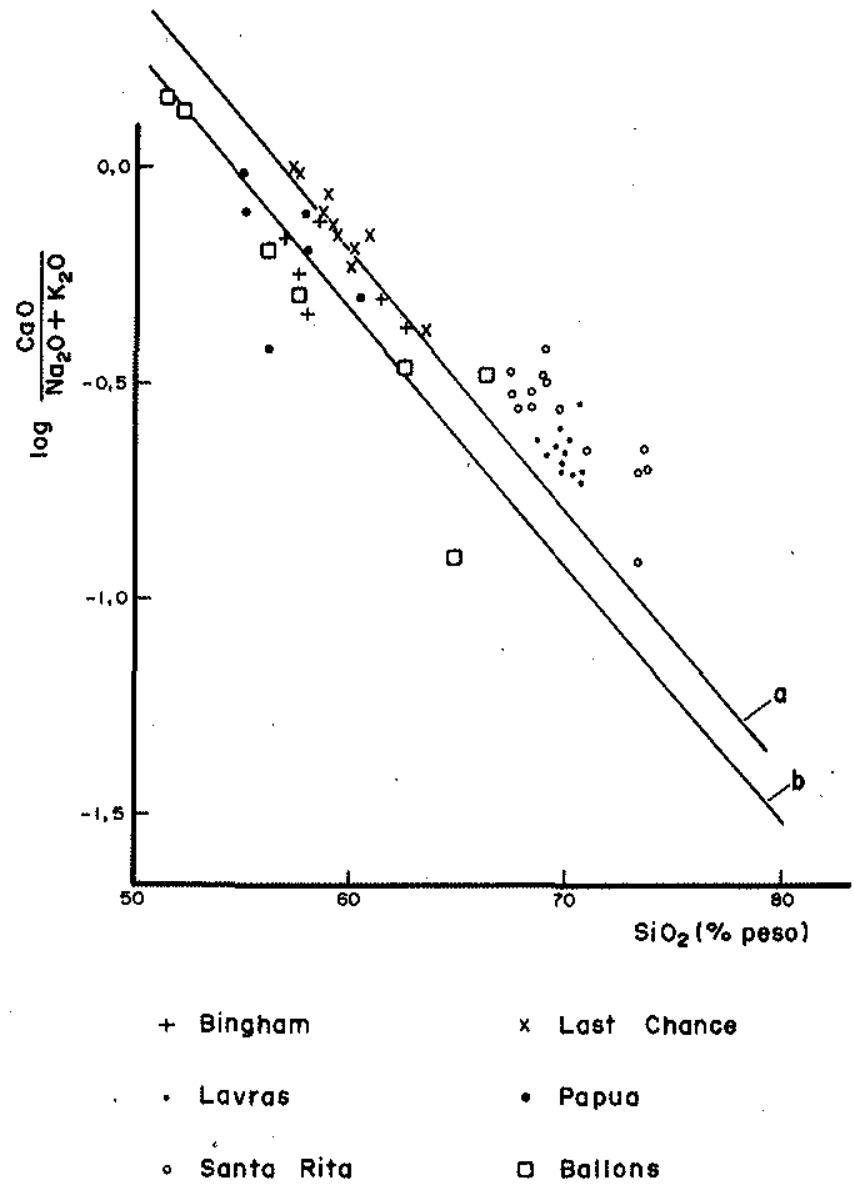

Figura 2 - Comportamento de granitoides da série shoshonitica no diagrama sugerido por Brown (1982). A linha superior assinala o limite inferior do campo dos granitóides de arco-de-ilhas (a) e a inferior, dos de margem continental (b). Referências como na tabela 1 .

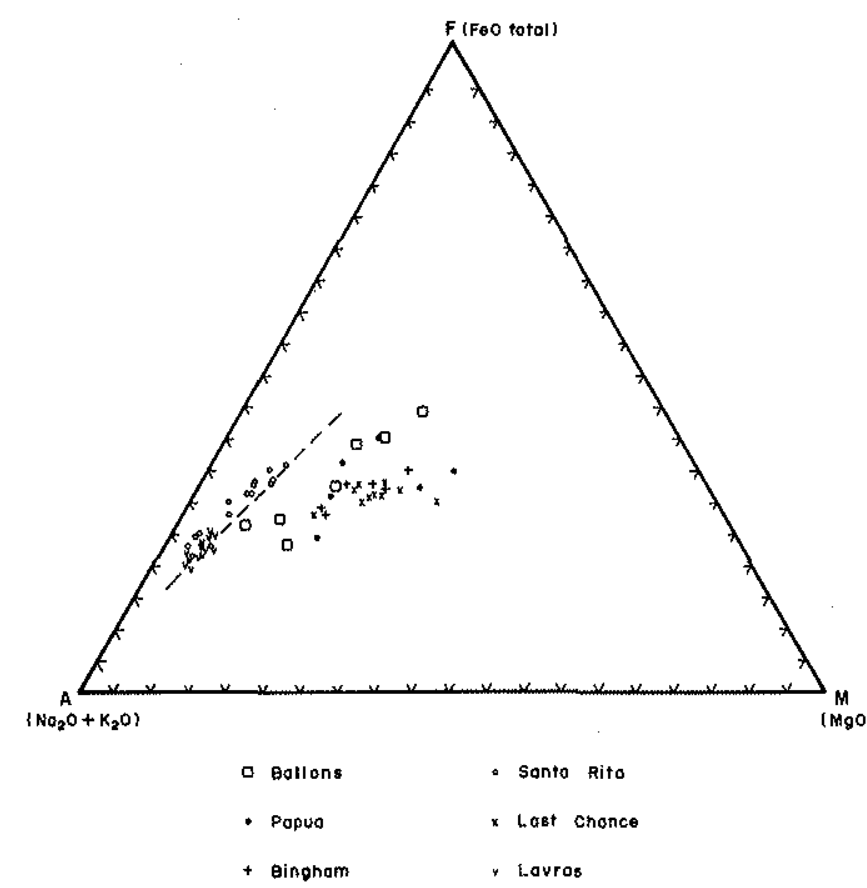

Figura 3 - Granitóides de série shoshonitica no diagrama AFM (Brown 1981). A linha tracejada assinala o limite do campo dos granitóides da série alcalina (menos magnesianos) e da série cálcio-alcalina. Referências como na tabela 1 
No diagrama de Wright (1969), representado na figura 4. os granitóides da série shoshonítica situam-se principalmente no campo dos granitóides da série alcalina, próximo ao limite com o campo dos granitóides da série cálcio-alcali. na.

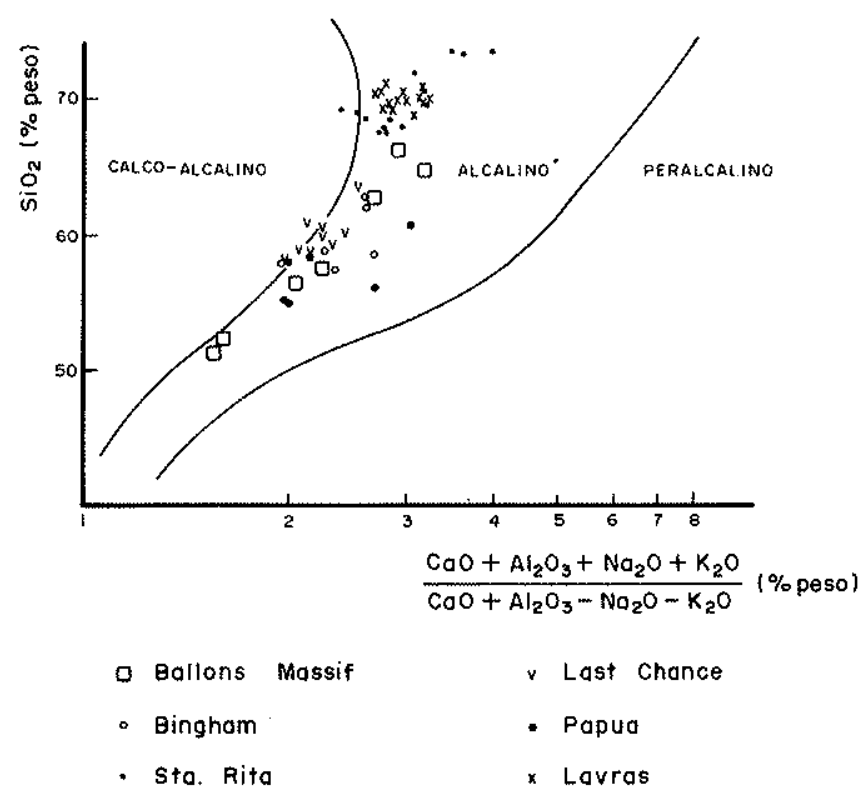

Figura 4 - Representação de granitóides da série shoshonitica no diagrama de Wright (1969). Referências como na tabela 1

A figura 5 mostra o comportamento desses granitóides no diagrama de Rogers \& Greenberg (1981), observando-se que os teores relativamente elevados de $\mathrm{K}_{2} \mathrm{O}$ os colocam fora ou no limite do campo dos granitóides da série cálcioalcalina.

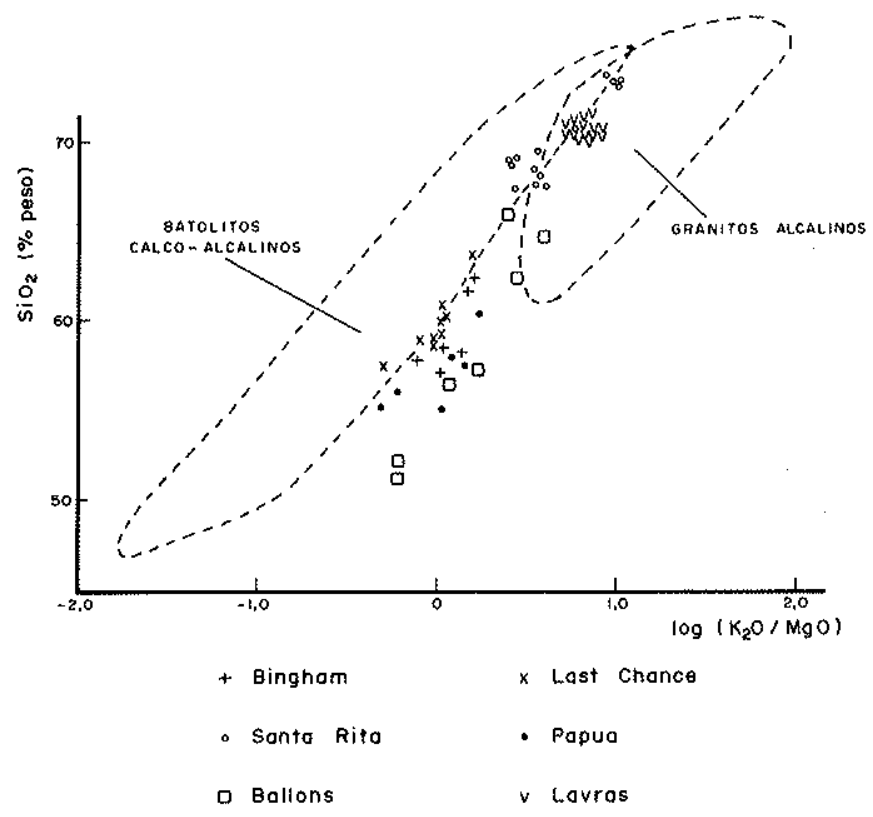

Figura 5 - Comportamento de granitóides daa série shoshonitica no diagrama de Rogers \& Greenberg (1981). Referências constam na tabela 1
Os diagramas precedentes sugerem que as rochas granitóides da série shoshonítica apresentam um caráter que pode ser descrito como transicional entre as séries cálcio-alcalina e alcalina, o que é devido ao teor relativamente elevado de $\mathrm{K}_{2} \mathrm{O}$ contido nestas rochas.

É importante ressaltar que os valores elevados da razão $\mathrm{K}_{2} \mathrm{O} / \mathrm{Na}_{2} \mathrm{O}$ normalmente encontrados nos termos básicos $\mathrm{e}$ intermediários da série shoshonítica não se verificam entre os termos mais diferenciados que podem apresentar valores inferiores a 1,0 para esta razão.

Conforme observaram Pagel \& Laterrier (1980) no maciço de Ballons, nas demais associações estudadas os teores de $\mathrm{Al}_{2} \mathrm{O}_{3}, \mathrm{Fe}$ (total), $\mathrm{MgO}$ e $\mathrm{CaO}$ decrescem progressivamente ao longo da diferenciação magmática.

Os elementos-traços constituem parâmetros mais eficazes que os elementos maiores na caracterização dos granitóides de séries shoshoniticas. Entre eles, os elementos litófilos de grande raio iônico $\mathrm{Ba}, \mathrm{Sr}$ e $\mathrm{Rb}$ mostram enriquecimento acentuado nesses granitóides (Tab. 1), embora nos termos muito diferenciados $\left(\mathrm{SiO}_{2}\right.$ em torno de $\left.73 \%\right)$ ocorram por vezes reduçōes bruscas especialmente nas concentraçōes de $\mathrm{Sr}$ e $\mathrm{Ba}$. Elevadas concentrações de $\mathrm{Ba}$ e $\mathrm{Sr}$ são registradas em granitóides arqueanos (Condie 1982), entretanto, além de os teores serem geralmente mais baixos que nas séries shoshoníticas, também as concentrações de $\mathrm{Rb}$ e $\mathrm{K}_{2} \mathrm{O}$ são relativamente baixas. Comparativamente com os granitóides da série cálcio-alcalina, as altas concentrações dos três ele. mentos traços citados constituem o critério distintivo mais significativo. De acordo com os dados de Tauson (1983), os termos graniticos mais diferenciados da série shoshonítica (em torno de $73 \%$ de $\mathrm{SiO}_{2}$ ) podem apresentar concentraçōes de $\mathrm{Ba}$, $\mathrm{Sr}$ e $\mathrm{Rb}$ similares aos granitóides ultrametamórficos, que também apresentam razões $\mathrm{K}_{2} \mathrm{O} / \mathrm{Na}_{2} \mathrm{O}$ elevadas. $\mathrm{Na}$ distinção desses dois grupos podem ser utilizados elementos como $\mathrm{Zr}$, $\mathrm{Nb}$ e $\mathrm{Y}$, que tendem a ocorrer em baixas concentrações em produtos de anatexia. Já nos granitóides da série shoshonítica seus teores são relativamente elevados, embora muito abaixo dos encontrados nas rochas graníticas da série alcalina. Tauson (1983) salientou ainda que os granitóides da série shoshonítica, referidos como série latítica, apresentam concentrações elevadas de voláteis $\left(\mathrm{H}_{2} \mathrm{O}, \mathrm{F}, \mathrm{Cl}\right.$, $\mathrm{B}, \mathrm{CO}_{2}$ e S).

Pearce et al (1984) apresentaram diagramas baseados em elementos-traços utilizáveis na discriminação de granitóides de diferentes ambientes tectônicos. Os granitóides da série shoshonítica foram incluídos entre as rochas graníticas de arcos vulcânicos e margens continentais. A figura $6(a, b)$ mostra que o padrão dos granitóides da série shoshonítica é semelhante aos dos granitóides do Chile citados por aqueles autores; na figura $6 \mathrm{c}$, as rochas graníticas da zona central do Complexo Granítico Lavras situam-se no topo do campo dos granitóides de arcos vulcânicos, muito próximas aos campos dos granitóides intraplacas e de zonas de colisão.

A figura 7 ilustra o comportamento das terras-raras nos granitóides shoshoníticos do Rio Grande do Sul. Tanto no que se refere à abundância como no grau de fracionamento e ausência de anomalias de Eu pronunciadas, eles se assemelham aos granitóides da série cálcio-alcalina. Nardi (1984) observou que a maioria dos granitóides de séries cálcio-alcalinas apresenta teores de $\mathrm{Ce}$ padronizados pelo padrão condrítico em torno de 80 , e razão $\mathrm{CeN}_{\mathrm{N}} / \mathrm{Yb}_{\mathrm{N}}$ (N significando que o teor foi padronizado pelo padrão condrítico) 
(a)

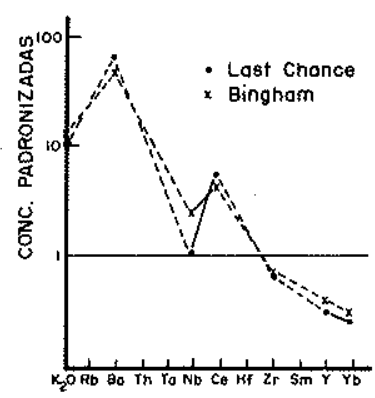

(D)

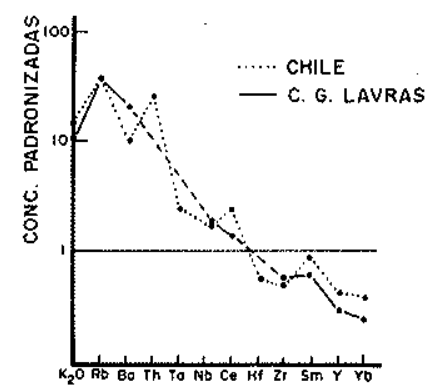

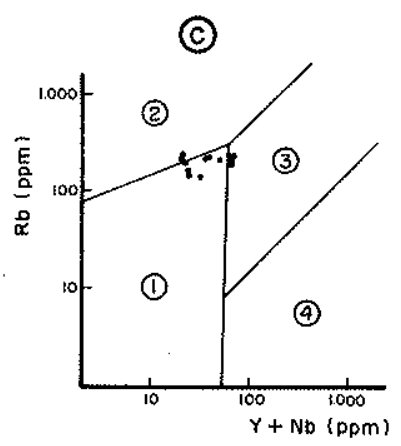

Figura 6 - a) Granitóides de Last Chance e Bingham representados nos diagramas utilizados por Pearce et al. (1984); b) granitóides da zona central do Complexo Granitico Lavras comparados aos granitóides do Chile referidos pelos citados autores; c) diagrama de Pearce et al. (1984) discriminando os campos dos granitóides: 1 de arco-de-ilhas; 2. sin-colisionais; 3 . intraplacas; $e$ 4. das cadeias oceânicas. Os pontos representam granitóides da zona central do Complexo Granitico Lavras

(Hanson 1980) maior que 10. Já os granitóides da série alcalina apresentam concentração mais elevada de terras-raras, baixo grau de fracionamento $\left(\mathrm{Ce}_{\mathrm{N}} / \mathrm{Yb}\right.$ geralmente menor que 10 ) e acentuadas anomalias negativas de Eu. Girod (1978b) salientou a semelhança dos padrões de terras-raras nas rochas vulcânicas da série shoshonítica e da cálcio-alcalina.

Nos granitóides mais diferenciados da série shoshonítica, com teores de $\mathrm{SiO}_{2}$ da ordem de $73 \%$, o decréscimo acentuado de $\mathrm{Ba}$ e Sr pode ser explicado por fracionamento de feldspato potássico ou plagioclásio e biotita. Neste caso, a geração de anomalias de Eu pode ser inibida pelaalta concentração de $\mathrm{Ba}$ e $\mathrm{Sr}$ no sistema, como sugerem Birk et al. (1979).

Os dados referentes a elementos-traços em granitóides de séries shoshoniticas disponiveis atualmente não permitem a formulação de hipóteses mais conclusivas ou maiores generalizações As características geoquímicas, petrológicas e isotópicas das rochas vulcânicas da série shoshonítica sugerem que as mesmas são geradas por fusões parciais de materiais do manto enriquecidos de elementos litófilos de grande raio ionnico (Girod 1978, Baker 1978, Carr \& Fardy 1984). Este enriquecimento pode estar relacionado com a subduc. ção de crosta oceânica (Pearce 1983). Outros autores admi- tem que os magmas shoshoniticos são principalmente mantélicos, mas o enriquecimento nos elementos citados é decorrente da assimilação de rochas crustais (Tsvetkov 1984). De acordo com Nardi (1984), as características geoquímicas das rochas da zona central do Complexo Granítico Lavras são compatíveis com uma gênese a partir de magmas gerados por fusão parcial de materiais mantélicos portadores de granada.

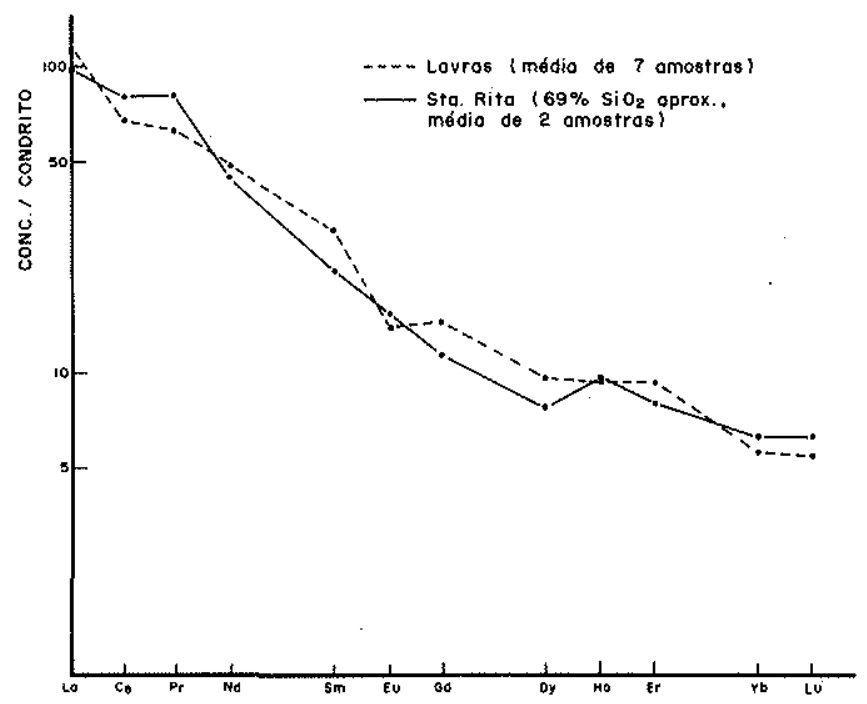

Figura 7 - Conteudos de terras-raras do Monzogranito Santa Rita e zona central do Complexo Granitico Lavras padronizados em relação àos valores médios de condritos

Metalogenia A potencialidade metalogenética das rochas graníticas da série shoshonitica é de difícil constatação devido à dificuldade de caracterização das mesmas. Para demonstrá-las, foram selecionados três exemplos de mineralizaçōes que, neste trabalho, são considerados como associados a granitóides da série shoshonítica.

As instrusões monzoníticas e quartzo-monzoníticas de Bingham, contendo até $65 \%$ de $\mathrm{SiO}_{2}$, são geradoras de mineralizaçōes do tipo cobre pórfiro que já produziram quantidade superior a 10 milhões de toneladas de cobre e mais os subprodutos: ouro, prata, molibdênio, chumbo e zinco, entre outros. Essas rochas são intrusivas em mármores e mostram uma zonação distinta $\mathrm{Mo}, \mathrm{Cu}, \mathrm{Cu}-\mathrm{Pb}, \mathrm{Pb}-\mathrm{Zn}$ do núcleo para as bordas da zona mineralizada. A alteração hidrotermal manifesta-se como propilitização, alteração potássica e sericitização localizada nas zonas de fraturamento (Lanier et al. 1978).

O denominado Mount Fubillan ou Ok Tedy Porphyry Copper Deposit (Bamford 1972) constitui o mais jovem depósito do tipo cobre pórfiro em Papua-Nova Guiné. A mineralização é associada a monzonitos e granodioritos intrusivos em espessas seqüências dominantemente piroclásticas. A alteração hidrotermal dominante é potássica sendo a sericitização $\mathrm{e}$ a argilização restritas às proximidades das intrusões.

A Associação Shoshonítica de Lavras do Sul apresenta 
mineralização de cobre-ouro, com zonação semelhante à descrita em Bingham. Lima (1985) considerou-a como do tipo cobre pórfiro. Nas rochas graníticas predominam as alterações propilíticas e sericíticas (Nardi 1984) enquanto na sequiência vulcânica a propilitização é o tipo mais importante (Lima 1985). A mineralização desta região é atual objeto de pesquisas visando seu dimensionamento.

Tauson (1983) enfatizou a potencialidade metalogenética das rochas da série shoshonítica e relacionou com a mesma importantes depósitos de cobre, molibdênio, estanho, tungstênio, chumbo, zinco e outros.

CONSIDERAÇÕES FINAIS A geoquímica dos elementos maiores pode auxiliar na determinação do caráter shoshonítico dos granitóides, particularmente no caso dos menos diferenciados, quando o diagrama de Peccerillo \& Taylor (1976) e os parâmetros de Morrison (1980) são efetivos.

As dificuldades tornam-se maiores para rochas que atingiram um maior grau de diferenciação, neste caso os teores de elementos-traços $\mathrm{Ba}, \mathrm{Sr}, \mathrm{Rb}, \mathrm{Zr}, \mathrm{Y}$ e $\mathrm{Nb}$ assumem uma função de destaque. Finalmente, para termos muito diferenciados com teores de $\mathrm{SiO}_{2}$ da ordem de $74 \%$, o critério mais objetivo até o momento é o da associação e continuidade de trends nos diagramas discutidos.

Grande parte dos dados geoquímicos disponiveis para as rochas da série shoshonítica sugere que as mesmas seriam termos transicionais entre a série cálcio-alcalina e alcalina. Entretanto o exame mais detalhado do comportamento das terras-raras e dos demais elementos-traços discutidos anteriormente parece indicar que estas rochas constituem um grupo com características próprias que refletem condições específicas necessárias para a sua geração. Neste sentido, a afirmação đe Morrison (1980), relativa à importância geotectônica das mesmas, parece coerente, mas devendo, no entanto, ser fundamentada em um maior número de observações, particularmente em áreas pré-cambrianas.

$\mathrm{O}$ exame preliminar de dados geoquímicos referentes a diversas associações graníticas sugere a possibilidade de as mesmas terem tido afinidade shoshonítica, como, por exemplo, os granitóides de Três Córregos, Itaoca e Cunhaporanga na região da Ribeira nos Estados de São Paulo e Paraná (Gomes et al. 1975), plútons monzoníticos da Califórnia (Miller 1978), o Allard Stock no Colorado, portador de mineralização do tipo cobre pórfiro (Werle et al 1984), e outros.

Agradecimentos $\mathrm{O}$ autor expressa seu reconhecimento pelas valiosas sugestðes do Prof. Evandro F. de Lima e pela revisão da Prof. a Maria de Fátima Bittencourt. As pesquisas envolvidas neste trabalho foram financiadas pelo Conselho Nacional do Desenvolvimento Científico e Tecnológico (CNPq) e pela Financiadora de Estudos e Projetos (Finep).

\section{REFERENCIAS BIBLIOGRAFICAS}

ARNDT, N.T. \& NISBET, E.G. - 1982 - What is a komatiite In ARNDT, N. T. \& NISBET, E.G. eds. Komattites. New York. George Allen \& Unwin. 526 p.

BARKER, P. - 1978 - Pétrologie des laves dans les zones de subduction. In: GIROD, M. ed Les roches volcaniques. Paris, Doin Editeurs. p. 136-165.

BAKER, P. - 1982 - Evolution and classification of orogenic volcanic rocks. In: THORPE, R.S. ed. Andesites. New York, John Wiley \& Sons. p. 11-21.

BAMFORD, R.W. - 1972 - The Mount Fubillan (Ok Tedy) Porphyri Copper Deposit, Territory of Papua and New Guinea. Econ. Geol., 67(8):1019-1033.

BIRK, D.; KOLJONEN, T.; ROSENBERG, R.J. - 1979 - Rareearth distribution in Archaean plutons of the Wabiggon volcanic-plutonic belt, northwestern Ontario. Can. J. Earth Sci., 16:270-289.

BROWN, G.C. - 1981 - Space and time in granite plutonism. Phil. Trans. R. Soc. London., A301:321-336.

BROWN, G.C. - 1982 - Calc-alkaline intrusive rocks: their diversity, evolution, and relation to volcanic arcs. In: THORPE, R.S. ed. Andesites. New York, John Wiley \& Sons. p.437-461.

CARR, P.F. \& FARDY, J.J. - 1984 - REE geochemistry of Late Permian Shoshonitic lavas from the Sidney Basin, New South Wales, Australia. Chem. Geol, 43:187-201.

CHAPPELL, B.W. \& WHITE, A.J.R. - 1974 - Two contrasting granite types. Pacific Geol, 8:173-174.

CONDIE, K.C. - 1982 - Archaean Greenstone Belts. New York, Elsevier. $434 \mathrm{p}$.

EWART, A. - 1979 - A review of the mineralogy and chemistry of Tertiary - Recent dacitic, latitic, thyolitic, and related salic volcanic rocks. In: BARKER, F. ed. Trondhjemites, dacites and related rocks. Oxford, Elsevier. p.13-121.

GIROD, M. - 1978 - Les séries magmatiques In: GIROD, M. ed. Les roches volcaniques. Paris, Doin Editerus. p.7-30

GIROD, M.; - 1978 - Series volcaniques et tectonique des plaques GIROD, M. ed. Les roches wolcaniques. Paris, Doin Editeurs. p. 74-96.
GOMES, C.B.; ARRUDA, J.R.; BERENHOLC, M.; HYPOLLTTO, R. - 1975 - Geoquímica de maciços graníticos da região da $R$ ibeira. Parte II: Elementos Traços. An. Acad. bras. Cienc. 47:459-476.

HANSON, G. - 1980 - Rare elements in petrogenetic studies of igneous systems. Ann. Rev. Earth Planet. Sci., 8:371-406.

HUBREGTSE, J.J.M.W. - 1976 - Volcanism in the Western Superior Province in Manitoba. In: WINDLEY, B.F. \& TARNEY, J. eds. The early history of the earth. Londres, John Wiley \& Sons. p. 279:287.

HUGHES, C. - 1982 - Igneous Petrology. New Yotk, Elsevier. 551 p.

ISHIARA, S. - 1977 - The magnetite-series and ilmenite-series granitic rocks. Ming. Geol, 27:293-305.

JAKES, P. \& WHITE, A.J.R. - 1972 - Major and trace element abundances in volcanic rocks of orogenic areas. Bull. Geol. Soc. America, 83:29-49.

JOPLIN, G.A. - 1965 - The problem of the potash-rich basaltic rocks. Mineral. Mag., 34:266-275.

LAMEYRE, J. - 1980 - Les magmas granitiques: leurs comportements, leurs associations et leurs sources. Soc. Geol. France. Mem., 10:51-62.

LAMEYRE, J. \& BOWDEN, P. - 1982 - Plutonic rock type series: Discrimination of veious granitoid series and related rocks. $J$. Volcanol. Geotherm. Res., $14: 169 \cdot 186$

LANIER, G.; JOHN, E.C.; SWENSEN, A.J.; REID, J.; BARD' C.E.; CADDEY, S.W.; WILSON, J.C. - 1978 - General geology of the Bingham Mine, Bingham Canion, Utah. Econ. Geol., 73:1228-1241.

LIMA, E.F. - 1985 - Petroquímica e prospecção litogeoquímica da área da Merita, região de Volta Grande, Lavras do Sul, RS. Porto Alegre (Universidade Federal do Rio Grande do Sul. Dissertação de Mestrado). $187 \mathrm{p}$.

MILLER, C.F. - 1978 - Monzonitc plutons, California, and a model for generation of alkali-rich, near silica saturated magmas. Contrib. Mineral. Petrol, 67:349-355.

MIYASHIRO, A. - 1974 - Volcanic rock series in island arcs and 
active continental margins. Am. J. Sci, 274:321-355.

MOORE, W.J - 1973 - Igneous rocks in the Bingham Mining District Utah. Geol. Surv. Prof. Paper, 629B. 42p.

MORRISON. G.W. - 1980 - Characteristics and tectonic setting of the shoshonite rock association. Lithos, 13:98-108.

NARDI, L.V.S. - 1984 - Geochemistry and Petrology of the La. vras Granite Complex, RS, Brasil. Londres, Tese de Doutorado, Universidade de Londres). $268 \mathrm{p}$.

NARDI, L.V.S. \& LIMA, E.F. - 1985 - A Associaçāo Shoshonítica de Lavras do Sul, RS. Rev. Bras. Geoc., 15(2):139-146.

NAUMANN, M. - 1985 - O Complexo iulcânico sedimentar de Ibaré, RS. Porto Alegre (Dissertação de Mestrado, Universidade Federal do Rio Grande do Sul). 150p.

PAGEL, M. \& LETERRIER, J. - 1980 - The subalkaline potassic magmatism of the Ballons Massif (Southern Vosges, France): shoshonitic affinity. Lithos, 13:1-10.

PEACOCK, M.A. - 1931 - Classification of igneous rock series. $J$. Geol. Chicago, 39:54-67.

PEARCE, J. - 1982 - Trace element characteristics of lavas from destructive plate boundaries. In: THORPE, R.S. ed. Andesites. New York, John Wiley \& Sons. p.525-548.

PEARCE, J. - 1983 - Role of the subcontinental lithosphere in magma genesis at active continental margins. In: HAWKESWORTH, C. \& NORRY, W.J. eds. Continental basalts and mantle xenoliths. London, Shiva Publ. p.230-250.

PEARCE, J.A.; HARRIS, N.B.W.; TINDLE, A.G. - 1984 - Traceelement discrimination diagrams for the tectonic interpretation of granitic rocks. J. Petrol., $25: 956-983$.

PECCERILLO, E. \& TAYLOR, S.R. - 1976 - Geochemistry of
Eocene calc-alkaline volcanic rocks from the Kastamonu areas, Northern Turkey. Contr. Mineral. Petrol., 58: 63-81.

ROGERS, J.J.; HODGES, K.; GHUMA, M. - 1980 - Trace elements in Ben Ghnema batholith and nature of the precambrian crust in central North Africa. Bull. Geol. Soc. America., $91: 1742-1788$

ROGERS, J.J. \& GREENBERG, J.K. - 1981 - Trace elements in continental margin magmatism. Part III. Alkali granites and their relationship to cratonization. Bull. Geol. Soc. America, 92:6-9.

SMITH, L.E. - 1972 - High-potassium intrusive rocks from South-eastern Papua. Contr. Mineral. Petrol, 34:167-176.

STRECKEISEN, A. - 1976 - To each plutonic rock its proper name. Earth Sci. Rev., 12:1-33.

TAUSON; L.V. - 1983 - Geochemistry and metallogeny of the latitic series. Inter. Geol. Rev., 25:125-135.

TSVETKOV, A.A. - 1984 - Subalkaline basaltic magmatism in active zones of transition from ocean to continent. Inter. Geol. Rev., 26:889-906.

WERLE, J.L.; IKRAMUDDIN, M.; MUTSCHLER, F.E. - 1984 Allard stock, La Plata Mountains, Colorado - an alkaline rock - hosted porphyry copper-precious metal deposit. Can.J. Earth Sci., 21:630-641.

WRIGHT, J.B. - 1969 - A simple alkalinity ratio and its application to questions of non-orogenic granite genesis. Geol. Mag., 106:370-384.

MANUSCRITO

Recebido em 10 de janeiro de 1986 Revisão aceita em 24 de fevereiro de 1986

Generalizações historicas são freqüentemente montadas pelos geólogos, mas e minha observação que elas raramente, se não nunca, são consideradas como proposiçóes que possuem força explanatória... As generalizaç̋es históricas... servem como guia... para a meta de formular os modos especificos de dependencia em termos de generalizaç̋es geológicas mais compreensiveis e, talvez, em altima análise, em termos de leis fisicas e quimicas. 